\title{
Incertezas de pacientes no sistema público de saúde
}

\section{$\mid{ }^{1}$ Diogo Neves Pereira |}

Resumo: Análises que objetivam compreender de que maneira sujeitos lidam com processos de saúde/doença geralmente dão ênfase aos modos como estes inserem suas vivências concretas em quadros avaliativos abstratos para, a partir daí, definirem ações a serem executadas. Isto posto, este artigo questiona o rendimento de tais abordagens no entendimento das experiências de pacientes do sistema público de saúde. As análises são empreendidas com base nos resultados de pesquisa realizada em instituição pública de saúde do Distrito Federal, na qual foram reconstituídos itinerários terapêuticos de seus pacientes. A pesquisa indicou que suas trajetórias são atravessadas por incertezas de diversas ordens. Tendo em vista a relevância destas e o fato de que de modo algum impedem o desenvolvimento de seus tratamentos médicos, o artigo discute como os pacientes lidam com essas incertezas e quais relações elas estabelecem com o conjunto de suas experiências. Argumenta então que suas incertezas derivam não de características imanentes a estes sujeitos, mas das relações que estabelecem com os saberes médicos e com as organizações institucionais para efetivação desses saberes, constituídas pelas instituições públicas de saúde. Mais além, demonstra que as apreciações, classificações etc. dos pacientes não se dirigem principalmente aos processos de saúde/doença em sentido estrito, mas aos mecanismos que possibilitam relaçóes de maior sucesso com as organizações institucionais por meio das quais eles obtêm seus tratamentos.

> Palavras-chave: experiências de saúde/doença, incertezas, pacientes do sistema público de saúde.
1 Doutorando do Programa de Pós-Graduação em Antropologia Social da Universidade de Brasília. Endereço eletrônico: diogonp@gmail.com

Recebido em: 20/05/2009. Aprovado em: 29/11/2009. 


\section{Primeiras informações}

Em análises sobre processos de tratamento e cura culturalmente definidos, alguns autores argumentaram - de forma mais ou menos incisiva - que, diante da identificação de uma situação de doença, as pessoas procurariam alternativas terapêuticas de acordo com a causalidade atribuída à perturbação. Rivers (1924) forjou a tese da tripla causação (humana, espiritual e natural) e da diferenciação entre doenças graves e leves, existindo tratamentos específicos para cada uma destas classes. De forma análoga, Evans-Pritchard (1937) argumentou que, em seus diagnósticos, os Azande cruzariam causaçōes "naturais" com "místicas", também as colocando em relação com a gravidade conferida à doença, derivando daí o tratamento concebido como adequado. Sindzingre e Zempléni (1981) construíram a distinção entre causas instrumental, eficaz e última geradoras das doenças. Buchillet (1991) combinou o sistema de Sindzingre e Zemplèni com o proposto por Auge, que separa registros (ou esferas) dos efeitos e das causas, e os ofereceu como instrumento para se pensar comparativamente contextos diferenciados, além da utilização conjunta de alternativas terapêuticas. Loyola (1991) apontou as separações entre doenças espirituais e materiais, entre doenças do cotidiano, graves e desconhecidas e, finalmente, entre doenças relacionadas a força ou fraqueza e doenças relacionadas a equilíbrio ou desequilíbrio - cada uma destas classificações conformando condiçōes distintas de tratamento. Por seu turno, procurando estabelecer parâmetros para comparaçōes entre contextos culturalmente constituídos relativos a experiências de saúde/doença, Kleinman (1980) assinalou que trajetórias de tratamentos são constituídas a partir das múltiplas avaliações de causalidade, eficiência e prognóstico oferecidas por distintos sistemas de atenção à saúde em momentos diferentes e subsequentes. No estudo de vivências no âmbito da saúde/doença, estes e outros autores se assemelham de forma importante ao darem destaque para as avaliações levadas a cabo pelos sujeitos das experiências. Sob este prisma, tentativas de tratamento seriam conformadas a partir da inserção consciente de uma situação concreta num quadro avaliativo mais amplo que, por sua vez, indicaria açôes a serem executadas.

Nesse sentido, a ideia de que itinerários terapêuticos são construídos especialmente por meio do acionamento de alternativas terapêuticas escolhidas com base na atribuição de diferentes causas às doenças, ou então na avaliação de resultados obtidos por estas alternativas, tal como nas análises acima citadas, 
supõe, portanto, que os sujeitos destas experiências possuem notável compreensão do que se passa com eles, de seus atos e das consequências destes para com suas condições. Além de se perceberem doentes, identificariam suas doenças, julgariam suas causas, reconheceriam suas características mais importantes, suas relações com múltiplos outros fatores e calculariam os efeitos produzidos por intervenções igualmente variadas - enfim, ordenariam e classificariam suas doenças em quadros eminentemente simbólicos, mas com reverberações práticas. Contudo, apenas a identificação de uma classe de causação por si só implica o manejo de sintomas, de sistemas nosológicos, de esquemas etiológicos etc. Mais do que isso, requer a análise e adequação destes em casos concretos específicos. Por outro lado, a apreciação de resultados produzidos em diferentes formas terapêuticas não é possível sem que estas avaliações sejam acompanhadas de um relativo distanciamento para com estas alternativas, permitindo um julgamento que leva em conta e hierarquiza efeitos de procedimentos com pressupostos e objetivos distintos. Sendo assim, longe de serem óbvias ou intuitivas, tais formulações são fundamentalmente complexas, exigindo níveis consideráveis de conhecimento, clareza e autonomia.

Este artigo apresenta e discute um contexto cuja compreensão parece não se esgotar com elaborações teóricas tais como as anteriormente mencionadas. A partir de pesquisa realizada na maior instituição pública de saúde do Distrito Federal ${ }^{1}$ que objetivava reconstituir itinerários terapêuticos de pacientes de seus diferentes setores (emergência, internação e ambulatório) -, o texto expõe e analisa fluxos de experiências relacionadas à saúde/doença atravessados por incertezas. Neste cenário, o privilégio das avaliações e considerações dos pacientes do sistema público de saúde dirigidas às suas doenças se mostra insuficiente no que tange ao entendimento de seus itinerários terapêuticos. Uma vez que tais incertezas se apresentam com realçada relevância, objetiva-se aqui discutir como esses pacientes lidam com elas e quais relações estabelecem com o conjunto de suas experiências. Para tanto, a seguir são descritas as diferentes formas pelas quais estas incertezas se apresentam em seus itinerários terapêuticos, demonstrando que elas resultam das relaçóes estabelecidas por eles com os saberes médicos e com as organizações institucionais para efetivação destes saberes, constituídas pelas instituições públicas de saúde. Ao final, argumenta-se que suas elaborações simbólicas e ações práticas não dizem respeito especialmente aos processos de saúde/doença em sentido estrito, mas aos mecanismos que possibilitam relações de maior sucesso com as organizações institucionais por meio das quais eles obtêm seus tratamentos. 
A discussão aqui proposta se fundamenta em pesquisa ocorrida em 2007 no maior hospital público do Distrito Federal. ${ }^{2}$ Nele, milhares de pacientes são atendidos mensalmente em serviços dos mais diversos, vindos não só de Brasília (onde está localizado) e das cidades próximas, mas também de uma ampla área de influência que se estende principalmente pelos estados do Centro-Oeste e do Nordeste. Dada a variedade de suas funções, a multiplicidade de especialidades médicas que possui, a complexidade da demanda e os diversos problemas existentes na organização do sistema de saúde, a instituição acaba por lidar com casos que variam numa larga margem de complexidade.

Durante a pesquisa, foram realizadas 35 visitas à instituição, nas quais foi empreendida exploração etnográfica de seu funcionamento, além de terem sido efetuadas cerca de 50 entrevistas com pacientes. Com o consentimento dos entrevistados, estas foram gravadas e, posteriormente, transcritas para análise. Obedeciam a um roteiro semiestruturado que objetivava possibilitar ao entrevistado produzir uma narrativa de sua experiência de saúde-doença. A proposta era reconstruir seus itinerários terapêuticos a partir das histórias contadas por eles, dando destaque à forma como eles próprios interpretavam, vivenciavam e percebiam suas experiências. ${ }^{3}$ Para multiplicar e diversificar as perspectivas captadas pela pesquisa junto aos pacientes, foram empreendidas entrevistas nos diversos setores do hospital. Com alguns dos interlocutores, especialmente com os internados, foi possível estabelecer contatos em circunstâncias posteriores às das entrevistas, o que permitiu aprofundar a compreensão de seus itinerários terapêuticos. Além disso, na composição do grupo de entrevistados participaram apenas adultos, tendo sido mantido um relativo equilíbrio de gênero. Com o exame dos dados, observou-se que a maior parte deles era oriunda das classes populares, possuindo escolaridade e renda baixas. Por sua vez, de forma combinada às entrevistas, com a vivência etnográfica procurou-se não apenas registrar $o$ cotidiano da instituição, mas também captar percepções de funcionários e outros indivíduos envolvidos em sua dinâmica, sendo possível assim relacionar as narrativas dos pacientes com outros pontos de vista, juntamente com nossas próprias observações e vivências ali ocorridas. ${ }^{4}$

Naquele momento o objetivo era, por meio dos relatos dos pacientes, reconstruir seus itinerários terapêuticos, para então apreender os processos que ao 
longo do tempo envolviam suas experiências; ou, dito de outro modo, procuravase entender suas trajetórias, tomando-as enquanto processos cujos eventos, por estarem encadeados numa sequência temporal, se influenciam mutuamente. Ao fazê-lo, foi possível perceber que os esquemas teórico-explicativos relativos a saúde/doença estabelecidos com base nas avaliações de causas e consequências por parte dos sujeitos das experiências não eram capazes de elucidar a realidade com a qual nos deparávamos. Isso porque a dinâmica dos itinerários destes pacientes - do momento em que começam a se entender como doentes, até fases avançadas de seus tratamentos médicos - é permeada por desconhecimentos, dúvidas, ambiguidades, enfim, pelo que denominamos genericamente de incertezas.

A pesquisa indicou que, independentemente do tipo de tratamento a que esteja sendo submetida, a imensa maioria dos pacientes desconhece as causas de suas doenças. Não sabem quais são seus agentes causadores nem como eles atuaram. Isso é observado não apenas no momento em que iniciam suas buscas por tratamento nas instituições públicas de saúde, mas também ao longo dos tratamentos médicos. Vários inclusive os encerram e passam a se considerarem curados sem que alcancem tal conhecimento. Para buscarem tratamento, esta informação não se faz necessária, pois entendem que apenas com o tempo os médicos identificarão as causas. Acreditam que somente os exames médicos podem desvelá-las e, como não são capazes de produzi-los ou interpretá-los, realizam seus tratamentos ignorando-as. Estão sempre esperando que os médicos as encontrem, para em seguida os informarem sobre elas. Associadamente, é comum que os pacientes permaneçam longos períodos sob cuidados médicos sem que um diagnóstico seja produzido, o que não impede que algum tratamento seja realizado. Porém, mesmo que o diagnóstico exista, não necessariamente a causa da doença é caracterizada, havendo apenas uma descrição da perturbação em termos médicos. Os pacientes podem conhecer seus diagnósticos, mas em geral não os compreendem em profundidade, tendo consciência tão somente de algumas nomenclaturas e de poucas relações. Eles não buscam os serviços médicos porque imaginam que estes profissionais os ajudariam a resolver um problema previamente caracterizado. Procuram os serviços médicos porque possuem problemas que não sabem caracterizar e manipular. A rigor, num certo ponto de vista, para tratar os pacientes não precisam estar lúcidos acerca destas problemáticas, necessitam apenas "fazer suas partes" - o que comumente significa cumprir as prescrições médicas, especialmente as medicamentosas. ${ }^{5}$ 
Não possuindo concepções acerca das origens de suas doenças formuladas com base na racionalidade médica científica ocidental, tampouco os pacientes se julgam capazes de avaliar os tratamentos médicos. Ocorre que eles não possuem critérios próprios com os quais possam produzir este tipo de apreciação. Identificam-se com a saúde em condiçóes melhores ou piores do que antes do tratamento, mas não sabem se estas mudanças são temporárias ou definitivas, ou então se elas se devem ou não às açôes médicas. Há uma série de incertezas relacionadas à organização de seus tratamentos: por que estes medicamentos, estes horários, estas dietas, estes toques etc. Quando suspeitam de que algo não vai bem em seus tratamentos, os pacientes não questionam o sistema terapêutico médico propriamente dito, mas no máximo as condições nas quais ele está sendo executado. Quando isso acontece, o que tentam fazer é prosseguir em suas buscas por tratamento em outras instâncias do serviço público de saúde. Nesse ínterim, a grande maioria apenas aprende ao longo do tempo como fazer com que seus tratamentos sejam mais bem realizados: como marcar consultas, como conseguir tempos menores de espera em filas, como serem transferidos para outras instituições etc.

As dúvidas com referência aos tratamentos são acompanhadas por desconhecimentos crônicos acerca do futuro. Prognósticos médicos precisos e detalhados são raros, de modo que as pessoas permanecem sem poder prever o que lhes acontecerá. Elas nutrem esperanças positivas, desejos de recuperação ou melhora, mas não sabem caracterizar o modo como isso pode ou deve se dar. Transferem aos médicos a competência de criar previsões, mas, quando eles as têm, nem sempre as explicitam aos pacientes e, quando o fazem, os pacientes absorvem seus prognósticos de forma precária, pois não compreendem perfeitamente seus princípios, pressupostos e implicações.

Em síntese, as experiências dos pacientes ao longo de seus itinerários terapêuticos são cercadas e atravessadas por inúmeras incertezas. Em qualquer momento estas dizem respeito ao passado, ao presente e ao futuro. Os pacientes têm clareza de que devem buscar tratamento e cooperar com ele - e frequentemente desenvolvem habilidades e aprendizados sobre tais questóes. Entretanto, carregam dúvidas acerca de suas doenças e de seus tratamentos: como eles surgiram, quais são suas etapas, seus prováveis efeitos, quais fatores são importantes para suas formações, quais relações estes fatores mantêm entre 
si e com outros quaisquer etc., o que em absoluto impede que seus tratamentos - e tampouco seus itinerários terapêuticos - se desenrolem.

Todavia, no interior deste horizonte de ignorâncias e estranhamentos, um elemento em especial merece discussão mais detalhada, pois de modo especialmente interessante coloca em relação as incertezas de pacientes e profissionais, a saber: os exames. Eles são quase onipresentes nos tratamentos médicos, sendo constantemente realizados e repetidos e podem possuir caráter exploratório - quando o médico pretende caracterizar com mais detalhes a situação do paciente - ou de monitoramento - quando o médico deseja avaliar ou identificar possíveis mudanças na condição do paciente. Em certos casos são realizados periodicamente, em intervalos de tempo estabelecidos de antemão; em outros ocorrem diariamente, sobretudo quando se entende que o estado do paciente é delicado e carece de atenção permanente. De acordo com o problema de saúde em questão e com a estratégia médica de tratamento, determinados exames são produzidos isoladamente, enquanto outros são combinados entre si para o delineamento de quadros mais minuciosos.

A presença dos exames é tão marcante que muitos pacientes lhes imputam a possibilidade da construção do diagnóstico médico. Por esta razão, a análise clínica, a sensibilidade ou a experiência do profissional por vezes são desvalorizadas. Neste bojo, por vezes a competência médica é percebida tão somente como capacidade técnica de interpretar exames. E quanto mais tecnologicamente complexos estes são, mais a leitura médica é apreciada e mais seus resultados são tidos como confiáveis. Alguns pacientes acreditam que quando o médico não solicita a realização de exames, ou então quando a instituição não possui os equipamentos necessários para fazê-los, impedindo assim que sejam efetivados, o diagnóstico e o tratamento correto se tornariam inviáveis. A ideia é que a realização dos exames seria uma precondição indispensável à boa prática da medicina.

A contrapartida desta perspectiva comum é um acirramento da incapacidade dos pacientes em compreender os tratamentos a que são submetidos, em conjunto com um alargamento das ambiguidades decorrentes desta incompreensão. Se a dinâmica dos tratamentos é associada aos resultados dos exames, e se a manipulação destes requer conhecimentos especializados que somente os médicos possuem, consequentemente, os pacientes se veem numa posição de desconhecimento e confusão. Alves e Rabelo (1999) argumentaram que a 
constituição das enfermidades requereria a transformação de aflições em objetos de reflexão e representação. Segundo eles, a objetivação da enfermidade passaria por seu destacamento para com o fluxo das vivências e para com o próprio sujeito, permitindo que seja tomada como totalidade distinta. Se agregarmos a esta proposição a dimensão intersubjetiva dos itinerários terapêuticos desses pacientes, percebemos que, ao menos neste caso em particular, tal distanciamento é efetivado pelo diagnóstico médico. Desde o início de sua busca por tratamento, o paciente começa a concretizar esta objetivação, mas são o diagnóstico e o estabelecimento de um tratamento que a consolidam. Entretanto, a entrada da ação médica no itinerário terapêutico do paciente gera um duplo distanciamento entre ele e a doença: se por um lado progressivamente transforma sensações suspeitas numa doença conhecida, por outro, caracteriza a doença como algo alheio à sua alçada de compreensão. Ele tem então de conviver ao longo de todo seu tratamento com incertezas relacionadas ao fato de que possui dificuldades para conjecturar opiniōes em torno do que vivencia.

Há uma ideia, propagada pela prática e pelo discurso de muitos médicos e geralmente compartilhada pelos pacientes - de que os exames ofereceriam a "verdade" da doença. O suposto é que existiria uma realidade objetiva por trás de sinais obscuros que poderia ser desvelada pelo exame, sendo esta sua função. Revelada esta realidade, o médico poderia então classificá-la, produzindo o diagnóstico. No entanto, o que este tipo de perspectiva não deixa transparecer é que os exames não espelham realidades independentes, mas antes constroem descriçóes relativas a determinados eixos compreensivos artificialmente concebidos. A suposição de que os exames oferecem "verdades" também oblitera que diagnósticos são sempre simplificações, processos de exclusão do que não se julga como importante e de realçamento do que se entende como relevante. É a admissão da possibilidade de que estas "verdades" existam que permite que os pacientes convivam com as incertezas. ${ }^{6}$ Se há uma "verdade", então apenas as perspectivas erigidas a partir delas são aceitáveis. Os médicos possuiriam a formação e os instrumentos necessários a alcançá-la e, assim, poderiam compreender e gerenciar os processos de tratamento. Aos pacientes, incapazes de atingi-la, restariam as imprecisões nas avaliações imaginadas.

Observa-se que, mais além, os pacientes desconhecem as razões de muitas das ações médicas a eles dirigidas porque não dominam os fundamentos teóricos 
de seus tratamentos. Não compreendem a fundo as motivações de eventos médicos pretéritos, presentes ou vindouros. Não sabem dizer por que os médicos solicitaram tais exames, por que é necessário esperar 20 e não 15 dias para serem operados, por que os medicamentos tiveram as doses aumentadas, por que seus "retornos" são marcados para cada dois meses, quais são os efeitos das injeções que lhes aplicaram, o que será feito com as porções de sangue que foram colhidas de seus braços etc. Acontece então de serem surpreendidos com ações que não esperavam. O medicamento que parecia estar funcionando bem é substituído, a previsão de alta é revista, o exame que há muito não era realizado é novamente requisitado etc. Estas surpresas geralmente são mais acentuadas quando surgem após cirurgias. Em algumas, são feitas intervenções nos corpos dos pacientes sem que eles as pudessem prever. Obviamente, parte delas se deve a imponderáveis que exigem ações imediatas, medidas que nem mesmo o médico poderia antecipar e cujo risco de ocorrência está implícito em todos os procedimentos do gênero. Contudo, acontece frequentemente de o paciente não ser informado sequer das possibilidades mais prováveis, podendo o cirurgião executar ações com relação às quais o paciente poderia ter sido consultado e, talvez, ter-se negado a se submeter. Mas em geral os pacientes ficam insatisfeitos somente quando estes fatos imprevistos representam algum tipo de incômodo: a colocação de uma sonda, o impedimento de receber alta, a necessidade de fazer algum exame ou tratamento desconfortável, o cumprimento de uma dieta pouco saborosa etc. Reclamações enfáticas acerca de mudanças no intervalo entre consultas ou nas prescrições de medicamentos, por exemplo, são raras.

Por estarem quase completamente dedicados a seus tratamentos, os pacientes em regime de internação no hospital pesquisado acabam por lidar mais intensa e constantemente com desconhecimentos. Por isso estão sempre esperando que durante suas visitas os médicos lhes informem algo sobre seus tratamentos. Aguardam estes contatos para que consigam alguma informação que lhes esclareça um pouco mais o que está acontecendo. Não esperam somente pelo momento em que os médicos descobrirão algo, mas também pela ocasião em que, adquirindo este conhecimento, se disponibilizem a compartilhá-lo. Esperam tais circunstâncias não apenas porque desejam conhecer as opiniões dos profissionais que cuidam de seus tratamentos, mas sobretudo porque desejam conhecer mais profundamente suas próprias situações. Vigora aí a noção de que os pacientes não 
precisam entender seus tratamentos para que eles se desenvolvam. Suas incertezas não os comprometeriam, do mesmo modo que a eliminação delas não colaboraria com a cura. A contribuição a ser oferecida pelos pacientes seria a cooperação, e não a compreensão. O que eles precisariam fazer seria seguir as indicaçōes médicas, sendo dispensável a apreensão de suas razões e fundamentos.

Com relação ao futuro, os pacientes estão sempre alimentando expectativas relativas aos próximos exames que realizarão. Acreditam que serão eles os fatores cruciais para a definição do porvir de seus tratamentos e de suas doenças. $\mathrm{O}$ curioso é que os exames anteriormente feitos não servem para extinguir as incertezas em torno do futuro. Esta eliminação é condicionada a exames posteriores, cujos resultados são também incertos. As informaçôes fornecidas pelos exames pretéritos são olvidadas pela chance de que os vindouros tragam alguma novidade. Parsons (1951) afirmou que as transformaçóes trazidas pelas doenças no âmbito dos padrões normais de vida das pessoas gerariam nelas ansiedade com relação ao futuro. Admitindo-se isso, no que se refere aos pacientes em questão, acrescentaríamos que esta ansiedade vem somada de inúmeras dúvidas. A absoluta maioria deles não sabe o que acontecerá com suas doenças e com seus tratamentos, estando sempre à espera de um próximo exame ou de uma próxima visita médica para que suas suspeições se esclareçam.

Ocorre de os pacientes sequer saberem quais doenças possuem, bem como quais são suas consequências, possibilidades de cura etc. Concebem que estes são assuntos médicos e que, por isso, são eles que devem formular e/ou conhecer as respostas. Desconhecem aspectos centrais de suas experiências até que, em certa oportunidade, sejam esclarecidos pelos médicos. E, a partir daí, a posição médica passa a atuar no cerne da experiência do paciente. Sua percepção da origem da doença se torna aquela informada pelo profissional, as características da doença percebidas são as apontadas por ele, as esperanças quanto ao futuro são pautadas pelo prognóstico médico etc. Numa situação limite, de acordo com alguns pacientes o conjunto dos exames realizados comporia o relato da história de seus problemas de saúde. Têm fé de que seus exames transportam verdades que tornam insignificantes suas ideias, sentimentos etc.

As incertezas chegam ao ponto de os pacientes se considerarem curados pelos tratamentos médicos sem que tenham tomado conhecimento de qualquer diagnóstico, sem que saibam por que ficaram doentes ou por que foram curados. 
Acontece também de persistirem em suas buscas por tratamento, mesmo que em diversas instituições ou com vários médicos uma mesma impossibilidade de tratamento tenha sido anunciada. E nestes casos não se trata tão somente de insistência. O paciente dificilmente tem plena consciência se de fato há ou não tratamento possível para sua doença, pois não possui critérios próprios que viabilizem tal avaliação.

A aceitação e o convívio com as incertezas, por parte dos pacientes, se devem sobretudo às noções relativas ao "papel de doente", 7 mas também a certa ideia de que os processos médicos de cura necessitam de tempo para serem efetivados, para que seus efeitos se realizem e possam ser percebidos. Sendo assim, confusões são amenizadas pela expectativa de que resultados positivos virão a seu tempo, e de que precisam dele para serem conseguidos. $\mathrm{O}$ paciente reconhece a necessidade deste tempo, mas não o domina. Entende que apenas o médico sabe manipulá-lo. Ele, sim, conheceria o tempo do medicamento, do exame, dos efeitos do tratamento, da doença etc.

Outra questão a ser explorada diz respeito ao fato de que em geral as instituições de saúde acumulam uma série de informações sobre seus pacientes que são julgadas relevantes do ponto de vista dos tratamentos médicos. Registram dados diversos por meio de cadastros e fichas que servem como instrumentos de identificação antes mesmo que o paciente receba algum tipo de atenção. Mas é com o prontuário médico que tais informações são agregadas de forma mais sistemática. Este constitui um documento de destacada importância que permanece arquivado durante certo tempo pela instituição. Intenta-se, por meio dele, conseguir controlar as mudanças ocorridas nas condições de saúde do paciente, pondo-as em perspectiva com as medidas terapêuticas adotadas. Teoricamente, nele seriam registradas todas as informaçóes que de alguma forma pudessem contribuir para que, a qualquer momento, a história do paciente fosse recuperada, sendo assim possível avaliar eventuais erros ou acertos cometidos. Porém, nem todos os dados são armazenados, muitos são utilizados momentaneamente e posteriormente descartados, outros são registrados de forma dispersa e se perdem antes de serem agregados etc. Há, assim, um déficit entre a quantidade de informações produzidas e as sistematicamente armazenadas. No entanto, é inequívoca a existência de uma intensa produção de informações sobre os pacientes. 
Embora esses documentos sejam produzidos na linguagem médica, são de domínio público e poderiam ser acionados pelos pacientes sempre que desejassem. Mas os pacientes quase nunca o fazem, ou quando têm contato com eles não os compreendem, o que a rigor significa que não tiveram acesso às informações que continham. Isso fica claro quando notamos o modo como se relacionam com seus exames. Muitos empreendem grandes esforços para conseguir realizá-los e, ao fazê-los, acreditam fortemente que trarão informações importantes sobre seus estados de saúde. Não obstante, quando têm diante de si seus resultados, quase sempre não conseguem interpretá-los - por vezes nem mesmo lê-los. Acontece de precisarem aguardar semanas ou até meses para que numa consulta médica sejam esclarecidos das informaçôes trazidas por um exame, vivenciando uma espera que comumente gera ansiedade e expectativa. Ele pode precisar esperar um tempo considerável para ser informado de que "está tudo bem", de que seus exames indicaram que sua condição de saúde está dentro dos padrões de normalidade estabelecidos, ou de que "nada foi encontrado". O entendimento destes resultados nem sempre envolve a posse de profundos conhecimentos especializados, mas, ainda assim, certa competência linguística é travestida em competência na capacidade do paciente de entender sua própria condição de saúde. Outro tipo de ocorrência comum é que os resultados dos exames não sejam entregues aos pacientes, ficando armazenados pelo hospital até que um médico os solicite a propósito de uma consulta. O suposto é que de nada adiantaria confiá-los aos pacientes. $\mathrm{O}$ encaminhamento direto para o médico seria pensado, portanto, como um conforto para o paciente, além de uma medida preventiva para evitar possíveis perdas ou extravios.

O nível de produção de informações sobre os pacientes não é, por conseguinte, equivalente ao patamar de informações absorvidas por eles. Num certo sentido, podemos conceber esta defasagem como sendo institucionalmente organizada. Não há interesse, por parte dos médicos ou das instituições, em esclarecer os termos dos tratamentos médicos aos quais os pacientes são submetidos. De forma associada, pouco se tenta traduzir as informações produzidas para uma linguagem inteligível aos pacientes. Note-se que os registros das passagens dos pacientes pelas instituições são sempre estruturados numa perspectiva médica, sobretudo através dos prontuários. Suas experiências, sentimentos ou pontos de vista não fazem parte deles. 
Por isso, sugere-se a existência de uma consciente gestão institucional das incertezas dos pacientes. Os profissionais sabem que seus pacientes convivem constantementecom elas. Também não existem dúvidas deque muitas delas poderiam ser eliminadas por meio de medidas simples de tradução ou de descentralização e publicização de informações. Boa parte das incertezas dos pacientes não deriva tão somente da falta de conhecimentos especializados, mas do modo como as instituições organizam a prestação de serviços médicos. Existe um desinteresse com a resolução delas, tendo em vista que, como afirmamos anteriormente, de certo ponto de vista seriam irrelevantes no que tange aos tratamentos. Goffman (1961) argumentou que uma das características das instituições totais é não apenas restringir as transmissões de informações entre seus mundos interior e exterior, mas também limitar o acesso dos internados aos planos e deliberações dos dirigentes, não permitindo que conheçam seus destinos. Esta postura concederia aos dirigentes uma distância e um instrumento de controle dos internados. Obviamente, em geral nossas instituições públicas de saúde estão distantes das características que definem, sob o prisma de Goffman, as "instituições totais", mas é interessante observarmos a presença de algumas semelhanças. A manutenção dos pacientes das instituições públicas de saúde com determinado patamar de desconhecimentos é funcional para a organização de seus tratamentos. A existência de um nível diferencial de saber garante prerrogativas de ação e de domínio.

$\mathrm{O}$ que os pacientes podem fazer diante deste contexto é confiar que os profissionais saberão lidar de forma eficiente com essas informaçôes, que as produzirão, interpretarão e utilizarão de maneira que lhes seja benéfica. Ademais, tentarão absorver, ainda que precariamente, as informações que lhes forem transmitidas, debaterão com outros pacientes e pessoas conhecidas acerca do que está lhes ocorrendo e imaginarão possíveis relações, eventos, efeitos etc. Mas se disporão a abandonar tais conjeturas quando assim um médico solicitar, ou quando alguma ação médica indicar que estavam erradas.

A face mais perversa deste conjunto de incertezas é provavelmente a impossibilidade de os pacientes avaliarem seus tratamentos médicos, o que inclui a privação de instrumentos de constatação de eventuais erros cometidos. Obviamente, quando, por exemplo, algum instrumento cirúrgico é esquecido dentro do paciente por ocasião de uma operação, ou então quando certo diagnóstico é fortemente desmentido em momentos posteriores da busca por tratamento, o 
paciente tende a avaliar que foi alvo de um equívoco. Entretanto, ainda assim pode nutrir dúvidas de que no fundo este "erro" possa ter sido causado pela falta de algum equipamento, pela fase em que sua doença se encontrava, ou simplesmente por um ponto de vista especializado diferente, mas igualmente legítimo. Afora estes casos paroxísticos, a maior parte dos erros médicos é diluída e obscurecida pelo fluxo dos tratamentos. Após um erro, o paciente busca tratamento em outra instituição, outro médico assume seu tratamento e o reinicia, os medicamentos são substituídos, o tempo passa e seu organismo se recupera, o paciente é curado etc. Desse modo, ainda que o paciente por alguma razão suspeite da existência de um erro, as incertezas com relação a ele fazem com que continue a se submeter ao tratamento. Quando isso não acontece, no máximo ele continuará sua busca por tratamento em outro lugar ou com outro médico. ${ }^{8}$ Por outro lado, vigora entre muitos pacientes a concepção de que como os médicos são especializados em determinadas partes do corpo ou problemas de saúde, seria natural e justificável que vez ou outra se equivocassem em suas ações. Eles não teriam a obrigação de obter sucesso em suas atitudes quando estivessem em jogo questôes com relação às quais não são peritos. Seriam igualmente desculpabilizados quando a "falta de recursos" ou de "estrutura" dificultasse seus trabalhos.

Se entendermos que a problemática das incertezas possuídas pelos pacientes ao longo de seus tratamentos médicos não deriva de características imanentes a eles, mas especialmente da relação que estabelecem com os médicos, seus tratamentos e saberes, teremos que nos voltar para esta relação se quisermos compreendê-la com mais profundidade. Fazendo isso, a primeira e mais geral constatação a que chegaremos é a de que, na relação entre médicos e pacientes, não há propriamente uma troca de saberes, experiências ou perspectivas. Na verdade, o que existe é um tipo específico de transmissão unilateral de pontos de vista. O contato entre eles é dominado pelos médicos, enquanto os pacientes permanecem quase plenamente na condição daqueles que observam, colaboram e, eventualmente, aprendem.

No entanto, esse "aprendizado" possui características muito particulares. Discutindo esta questão, Boltanski (2004) afirmou que o ponto central da relação entre médicos e pacientes é que eles podem ser originados de classes sociais diferentes, tendo trajetórias sociais distintas. Em sua maior parte, os médicos seriam membros de classes economicamente privilegiadas, enquanto a maioria dos pacientes integraria as classes populares. Quando uns e outros se encontram, 
os médicos tenderiam a adotar um modo simplificado de expressão, mas ainda assim os pacientes teriam dificuldades para compreender seus discursos. Eles não estudaram nas mesmas escolas, passaram por experiências formativas diferentes, não frequentam outros ambientes em comum etc. - enfim, uma infinidade de aspectos que tornam praticamente impossível aos pacientes apreenderem as taxonomias médicas, embora elas sejam as socialmente legitimadas. Para Boltanski, o que os pacientes fariam seria tomar partes fragmentadas do discurso médico - em especial aqueles termos mais próximos de outros já conhecidos - e as ressignificar de acordo com suas experiências e saberes. Aconteceria, nesse sentido, um processo precário e parcial de reinterpretação e ressignificação que Boltanski chamou de "reduções analógicas". Por sua vez, Machado (2003) destacou a possibilidade da conversão de distinções sociais em distinçôes de saber e, posteriormente, em elementos de legitimação da distância entre pacientes e médicos. As diferenças de classe, cor e linguajar seriam percebidas pelos médicos como marcadores de distinções sociais. Estas, por seu turno, seriam identificadas como índices da ausência ou posse de saberes especializados. A separação hierarquizada entre médicos e pacientes encontraria, portanto, apoio em certa percepção sobre diferenças sociais.

Em sintonia com esses autores e observando os itinerários terapêuticos dos pacientes do sistema público de saúde, foi possível perceber que, no decorrer de seus tratamentos, eles aprendem muito pouco da perspectiva dos médicos, ao mesmo tempo em que quase nada lhes ensinam. A comunicação entre eles é bastante restrita, praticamente se resumindo a avisos, explicações, ordens ou solicitações formuladas pelos médicos. Os pacientes tomam contato com uma porção muito maior de atividades às quais devem se submeter do que de diálogos acerca destas mesmas açóes. Por isso apreendem - no sentido do processo descrito por Boltanski - de forma precária o que lhes é transmitido, e agregam a estes entendimentos parciais conjuntos de incertezas referentes às outras esferas de seus tratamentos. Desse modo, o contato entre médicos e pacientes contribui muito pouco para que as incertezas destes últimos sejam sanadas.

Davis (1960), que enfrentou mais diretamente a problemática das incertezas na relação entre médicos e pacientes - focando-se na questão dos prognósticos oferecidos pelos médicos -, afirmou que em certos casos elas não derivam do nível de conhecimento do saber médico, mas do modo como este relacionamento 
está contextualmente estruturado. Em seu estudo, posta a constatação de que os médicos sabiam mais sobre determinada doença do que os pacientes em tratamento, a questão era verificar quanto de informação eles transmitiam, como estas informações eram comunicadas e como elas influenciavam expectativas acerca das doenças e das chances de recuperação. Sob este prisma, a questão importante do caso em questão é que as incertezas existentes do ponto de vista médico no início dos tratamentos, e que desapareceriam num segundo momento, passariam a ocupar - nas palavras do autor - uma "função administrativa", na medida em que certas informações não seriam transmitidas às famílias. A manutenção destas incertezas serviria como instrumento de redução de gastos adicionais com tempo e esforço por parte dos médicos, através da evitação do estabelecimento de relações francas e esclarecidas com as famílias. Sendo assim, a conclusão de Davis é que as incertezas clínicas dos médicos não seriam os fatores definidores da quantidade de informações comunicadas aos pacientes e às famílias. Outros elementos, interesses e circunstâncias participariam da conformação do prognóstico oferecido pelos médicos. Sendo assim, o que é exposto ao paciente como certo pode, realmente, ser incerto para o médico, e o que é apresentado como problemático pode, em verdade, não o ser.

Com base nesta constatação, Davis forjou o seguinte quadro esquemático, que pretende sintetizar a discrepância entre aquilo que os médicos sabem e o que dizem aos pacientes (1960, p. 46):

\begin{tabular}{|c|c|c|}
\hline & Certeza & Incerteza \\
\hline $\begin{array}{l}\text { Prognóstico é } \\
\text { oferecido ao } \\
\text { paciente }\end{array}$ & $\begin{array}{c}1 \\
\text { Comunicação }\end{array}$ & $\begin{array}{c}2 \\
\text { Dissimulação }\end{array}$ \\
\hline $\begin{array}{c}\text { Prognóstico não é } \\
\text { oferecido ao } \\
\text { paciente }\end{array}$ & $\begin{array}{c}3 \\
\text { Evasão }\end{array}$ & $\begin{array}{c}4 \\
\text { Admissão da incerteza }\end{array}$ \\
\hline
\end{tabular}

Fonte: Davis, 1960, p. 46

$\mathrm{Na}$ situação 1, o médico pode - de acordo com o estado presente do conhecimento médico e com sua própria habilidade - oferecer, de modo suficientemente compreensível, um prognóstico razoavelmente definitivo ao paciente e, de fato, o faz. Este seria o modelo ideal de relação entre médicos e pacientes. Na situação 2, o médico oferece ao paciente um prognóstico que 
não possui fundamento de acordo com seus próprios conhecimentos. Davis argumenta que esta não seria uma atitude rara, especialmente entre alguns profissionais que conceberiam que este é um artifício válido quando se pretende gerar algum tipo de alívio psicológico em casos não muito graves. Na situação 3, embora o médico possua um prognóstico razoável, não o transmite ao paciente. De acordo com o autor, a institucionalização informal desta prática estaria relacionada com uma estratégia de determinados profissionais que objetivaria eliminar questões "secundárias" de seus escopos de ação. Estratégia que seria fertilizada pela complexificação e especialização existentes nos grandes hospitais. Por fim, na situação 4 o médico não oferece qualquer prognóstico porque entende que nenhum é clinicamente justificável.

Davis não deixa de ponderar que seu esquema não pretende esgotar todas as possibilidades de relação entre médicos e pacientes, além de admitir que a postura do médico possa, em momentos diferentes, migrar de uma posição para outra durante um mesmo tratamento. Isto posto, utilizando suas assertivas na compreensão dos dados obtidos com a pesquisa cujos resultados são aqui apresentados, notamos que a postura dos médicos com os quais os pacientes se deparam está mais próxima da "evasão" do que de qualquer outra alternativa. Somente com os itinerários terapêuticos narrados pelos pacientes não é possível afirmar com exatidão em quais casos os médicos realmente não possuem prognósticos formulados ou em quais apenas não os transmitem. Porém, o certo é que quase sempre os pacientes não recebem estes prognósticos, precisando conviver a todo tempo com faltas de informações acerca do futuro. Além disso, muito raramente alguma dificuldade na análise da situação dos pacientes é admitida pelos médicos, o que nos leva a crer que a opção 3 provavelmente seja a que melhor represente esta realidade. Nesse sentido, as ideias de Davis nos auxiliam a perceber que as incertezas dos pacientes com relação aos seus tratamentos e suas prováveis condições de saúde futuras podem não ser equivalentes ao conhecimento ou desconhecimento dos médicos. A gestão destas incertezas pode estar mais relacionada com expectativas e demandas estabelecidas na dinâmica da relação entre médico e paciente do que com a capacidade do profissional de formular previsões com base em seus conhecimentos.

Desse modo, não paradoxalmente, apesar de se saberem envolvidos por todos estes desconhecimentos, estranhamentos, confusões etc., na maior parte das vezes os pacientes não deixam de executar as indicações médicas. Geralmente 
o fazem sem questionamentos, entendendo que, embora não compreendam as razões destas recomendações, elas serão positivas. Realizam exames, consomem medicamentos, fazem dietas, deixam de praticar atividades físicas etc., a despeito de não saberem exatamente por quê. Confiam na capacidade dos médicos de definirem ações que contribuam para um melhoramento da saúde. Por outro lado, percebe-se que para cumprir tais indicaçóes médicas, os pacientes precisam superar diversas dificuldades relativas à organização institucional de seus tratamentos. Para que, por exemplo, consigam agendar uma consulta, ou então fazer com que determinado encaminhamento chegue às mãos do médico adequado, é necessário que manipulem eficazmente os trâmites institucionais que organizam seus tratamentos.

Sendo assim, as generalizadas incertezas dos pacientes mantêm íntimas relações, por um lado, com certa posição de ascendência ocupada pelo saber médico no universo das experiências destas pessoas e, por outro, com a organização institucional da prestação de serviços. É possível percebermos a proeminência da condição hierarquicamente superior do saber médico nas menores ações dos atores envolvidos. Médicos visitam em grupo pacientes internados, conversam entre si acerca deles, mas não conversam com eles. ${ }^{9}$ Médicos examinam pacientes e não compartilham suas impressões, apenas entregam prescrições. Médicos executam consultas com pacientes (internados ou não) e sequer se apresentam. Pacientes internados devem parar qualquer coisa que estiverem fazendo e ficarem totalmente à disposição dos médicos que os visitam. Médicos não abrem mão de vestir jalecos brancos e pacientes precisam ficar despidos na frente de estranhos. Pacientes e médicos não se olham nos olhos quando se encontram - uns por vergonha, outros por desinteresse. E assim por diante. Apenas porque a principal função do paciente é cooperar com seu tratamento, suas incertezas não precisam ser eliminadas. Não se espera que ele compreenda o que se passa, mas somente que execute as ordens que recebe. $\mathrm{O}$ paciente se encontra na condição de alguém que não sabe nem mesmo o que está acontecendo com seu próprio corpo e que, portanto, carece de ajuda. Contudo, para obter tal auxílio, o paciente precisa executar tarefas diversas. Se escolher gerir seu tratamento tão somente por meio dos rumos institucionalmente definidos, muito provavelmente sofrerá prejuízos os mais variados - consultas desmarcadas, demoradas esperas, exames inadequados, alternância de médicos etc. Sabendo disso, o paciente em geral procura articular 
ações que possibilitem que sua busca por tratamento rapidamente alcance bom êxito. Para tanto, formulará estratégias para que a dinâmica institucional satisfaça com o menor custo possível as necessidades de seu tratamento tal como estabelecidas pelos médicos.

\section{Definições}

Confrontando este quadro com as perspectivas teóricas apontadas no princípio do texto - que dão ênfase às avaliações abstratas efetuadas pelos sujeitos que experimentam eventos de saúde/doença-, fica bastante clara a insuficiência dessas explicações para a compreensão deste contexto. Todavia, ainda assim poder-se-ia questionar como a existência destas incertezas não inviabiliza ou, pelo menos, não atrapalha a permanência dos pacientes do sistema público de saúde em seus tratamentos médicos. Mais do que isto, se poderia interrogar em que medida eles teriam ou não uma atitude consciente diante das incertezas.

Há, nesse campo de questôes, três aspectos a serem considerados. Inicialmente, e de modo mais amplo, é imperativo ter em mente que os pacientes não possuem uma postura eminentemente racionalista, teórica ou abstrata diante de suas incertezas. Seus engajamentos com relação a esta problemática em particular - mas também ao longo de seus itinerários terapêuticos - são práticos, não exigindo uma consciência absoluta de todos os fatores envolvidos. Eles não visam à adequação de suas realidades a regras constantes e abstratas, mas à manipulação razoavelmente coerente de relações e resultados em situações específicas. O que se nota é que os esquemas classificatórios em questão não existem fora nem tampouco apesar de vivências práticas pois, antes de qualquer coisa, estes são esquemas de uma só vez abstratos e práticos.

Já em âmbitos mais específicos, em primeiro lugar se deve considerar que é preciso tomar as perspectivas dos pacientes nas relações que estabelecem com os saberes médicos; em segundo lugar, é imperativo situar suas incertezas nos movimentos gerados pelas dinâmicas institucionais. Não é possível compreender seus itinerários terapêuticos levando em conta apenas suas avaliações abstratas. Faz-se necessário, por conseguinte, empreender um deslocamento de foco das avaliaçôes em torno das doenças para os saberes que de fato atuam sobre estas doenças e para o sistema social que regula a efetivação desses saberes. Se de modo algum as incertezas inviabilizam o desenvolvimento das experiências dos 
pacientes, devemos então reposicionar as bases nas quais se assenta este processo. Nesse sentido, o que se tem é o deslocamento das avaliações, apreciaçôes, estratégias etc. dos pacientes com base em saberes próprios ligados à experiência de saúde/doença para a relação que eles estabelecem com os saberes médicos e para os processos sociais que organizam suas execuções. Ou seja, as avaliaçóes em torno dos procedimentos de tratamento e cura são feitas pelos médicos, e não pelos pacientes. Todavia, elas são feitas a partir de certa operacionalização dos saberes médicos num sistema de saúde pública. É no estabelecimento de relações com este sistema que os pacientes devem se tornar especialistas, é aí que eles realizam avaliações, que medem causas e consequências, que ponderam efeitos, que aprimoram classificações etc.

Contudo, ao afirmar que nesse contexto curas são produzidas apesar das lacunas existentes no plano simbólico do ponto de vista do paciente, estaríamos estabelecendo um distanciamento entre um plano simbólico e um plano corporal? Ou, por outro lado, poderíamos estar repondo um grande divisor entre sociedades nas quais o simbólico agiria no corpo - em processos tais como os descritos por Lévi-Strauss (1958) - e outras, como a nossa, onde o corpo seria dominado pelo saber médico? Obviamente, poder-se-ia argumentar que entre nós a compreensão ou não do paciente para com sua condição de saúde/doença facilitaria ou prejudicaria o tratamento, mas não é isso que está em jogo. A questão é como fazer com que os planos simbólico e corporal se reencontrem analiticamente. Não se pretende esgotar aqui tal problemática, mas apenas assinalar que, ao menos no caso do paciente do sistema público de saúde, a junção entre os planos simbólico e corporal ocorre não na relação entre sua condição corporal e o plano de significados ligado à avaliação desta condição corporal em sentido estrito. Tal junção se dá, principalmente, na relação de seu estado corporal com o dispositivo de regulação e de relação entre saberes que opera o sistema público de saúde, pois este sistema é, mais do que apenas técnico, eminentemente simbólico.

Diante de suas incertezas, os pacientes não se veem estagnados até que elas sejam resolvidas; eles fazem o que julgam possível ser feito no momento e no sentido da resolução de seus problemas de saúde. Não trazem suas incertezas à consciência e lucubram em torno delas, mas as vivem imersas nas ações que empreendem e nas de outrem. Ou seja, não são as certezas (avaliações sobre causas, efeitos, relações entre elementos etc.) que mobilizam suas ações; são suas ações que 
regulam suas relações com as incertezas. Isso porque a ação prática não necessita ser acompanhada de uma consciência translúcida de todos os fatores envolvidos. Os pacientes não precisam ter uma compreensão teórica absoluta de todas as implicaçôes de seus tratamentos para deles participarem. Suas preocupaçôes se dirigem para as ações possíveis e não para as explicações irrefutáveis.

Nesse sentido, quando reconstruímos os itinerários terapêuticos de pacientes do sistema público de saúde, notamos que eles não expressam discursos sobre suas experiências de adoecimento, tratamento e cura que derivam de sistemas abstratos e transcendentes. Eles somente têm ciência do que fizeram e das motivações práticas e contextuais que os levaram a agir de tal ou qual modo. Olhando para trás, mapeiam a arena de atores dispostos em cada cenário, bem como as ações possíveis, e se recordam de que em cada momento somente fizeram o que acharam que deveria ser feito. Em suas experiências, o mais adequado não é refletir intelectualmente sobre saúde/doença, mas buscar tratamento. Após se caracterizarem como doentes, essas pessoas buscam o serviço público de saúde e, a partir daí, engajam suas ações nos direcionamentos médicos de seus tratamentos. Durante esse período, não se deterão demasiadamente em preocupações com incertezas, mas procurarão conseguir o maior sucesso possível em suas buscas por tratamento dentro das possibilidades dadas, até que os médicos informem que estão curadas.

Os pacientes do sistema público de saúde não formulam reflexões gerais sobre suas práticas de tratamento e cura; eles tentam resolver dificuldades imediatas apresentadas por problemas de saúde. Ainda que no interior de arquiteturas teóricas bastante diversas, Evans-Pritchard (1937), Young (1976) e Bourdieu (1980) já haviam alertado para o modo como a preocupação prática com a resolução de problemas particulares possibilita que eventos isolados corroborem ou sejam justificados pelos sistemas de pensamento e ação mais gerais no interior dos quais ocorreram. A atenção prática para com acontecimentos específicos impediria que dúvidas, erros ou refutações afetassem esses sistemas. Dessa forma, as incertezas e dificuldades enfrentadas pelos pacientes em seus itinerários terapêuticos são vividas como fatos isolados no interior de um esquema no qual se supõe que eles têm doenças, enquanto os médicos têm os saberes necessários à promoção de suas curas. Consequentemente, suas experiências negativas são tragadas pela concepção de que a medicina é seguramente o melhor modo de se lidar com as questões de saúde e doença. 
No decorrer deste processo, os pacientes têm internalizada a distância hierarquizada que separa suas perspectivas daquelas possuídas pelos médicos. Não suspeitam que a realidade poderia ser diferente. Não valorizam outros tipos de procedimentos e consideram sem sentido o questionamento do existente. No máximo questionam as condições institucionais de efetivação do saber médico. São relembrados então de que devem desacreditar nas outras práticas, nas outras visões, e inibidos de possuí-las. Isto posto, ao final de seus itinerários terapêuticos, os pacientes não enriqueceram possíveis noções próprias em torno de suas doenças, suas vidas, seus corpos, suas mortes etc. Seus itinerários terapêuticos não serviram de impulso ao desenvolvimento de práticas e classificações abstratas autônomas, mas de aprendizado precário acerca das perspectivas médicas e de aprimoramento de suas habilidades de como se servirem delas nos serviços públicos de saúde. Acentuam, assim, suas incertezas relacionadas aos saberes relativos às questôes de saúde/doença em sentido estrito, enquanto aprimoram suas certezas em torno das melhores estratégias de relacionamento com a dinâmica do sistema público de saúde.

\section{Referências}

ALVES, Paulo César B.; RABELO, Miriam Cristina M. Significação e metáforas na experiência da enfermidade. In: RABELO, M. C.; ALVES, P. C. B.; SOUZA, I. M. A. (Org.). Experiência de doença e narrativa. Rio de Janeiro: Fiocruz, 1999. p. 171-185.

BOLTANSKI, Luc. As classes sociais e o corpo. São Paulo: Paz e Terra, 2004.

BOURDIEU, Pierre. The Logic of Practice. Stanford, California: Stanford University Press, 1990.

BUCHILLET, Dominique. A antropologia da doença e os sistemas oficiais de saúde. In: BUCHILLET, D. (Org.). Medicinas tradicionais e medicina ocidental na Amazônia. Belém: CEJUP, 1991. p. 21-44.

DAVIS, Fred. Uncertainty in Medical Prognosis Clinical and Functional. The American Journal of Sociology, v. 66, n. 1, p. 41-47, 1960.

DUPUY, Jean-Pierre; KARSENTY, Serge. A invasão farmacêutica. Rio de Janeiro: Graal, 1974.

ELIAS, Norbert. O processo civilizador. V. 1 Uma história dos costumes. Rio de Janeiro: Jorge Zahar, 1994.

EVANS- PRITCHARD, Edward Evans. Bruxaria, oráculos e magia entre os Azande. Rio de Janeiro: Jorge Zahar, 2005. 
GOFFMAN, Erving. Manicômios, prisões e conventos. São Paulo: Perspectiva, 2005 (1961).

KLEINMAN, Arthur. Patients and Healers in the Context of Culture. An Exploration of the Boderland between Anthropology, Medicine and Psychiatry. Berkeley: University of California Press, 1980.

LÉVI-STRAUSS, Claude. O Feiticeiro e sua Magia. Antropologia Estrutural. Rio de Janeiro: Tempo Brasileiro, 2003 (1958). p. 193-214.

LÉVI-STRAUSS, Claude. A Eficácia Simbólica. Antropologia Estrutural. Rio de Janeiro: Tempo Brasileiro, 2003 (1958). p. 215-276,

LOYOLA, Maria Andréa. Medicina tradicional e medicinas alternativas. Representaçôes sobre a saúde e a doença, concepção e uso do corpo. In: BUCHILLET, Dominique (Org.). Medicinas tradicionais e medicina ocidental na Amazônia. Belém: CEJUP, 1991. p. 125-133. MACHADO, Lia Zanotta. Entre o inferno e o paraíso. Saúde, direitos e conflitualidades. Série Antropologia, n. 342, 2003.

PARSONS, Talcott. Social Structure and Dynamic Process: The Case of Modern Medical Practice. The Social System. New York: The Free Press, 1951. p. 428-479.

PEREIRA, Diogo Neves. Itinerários terapêuticos entre pacientes do Hospital de Base (DF). 2008. 203 p. Dissertação (Mestrado em Antropologia Social) - Departamento de Antropologia, Universidade de Brasília, Brasília, 2008.

RIVERS, W. H. R.. Medicine, Magic, and Religion. London: Routledge, 2001 (1924).

SINDZINGRE, N.; ZEMPLÉNI, A. Modèles et pragmatique, activation et répétition: réflexions sur la causalité de la maladie chez les Senoufo de Côte d'Ivoire. Social Science and Medicine, n. 15B, p. 279-293, 1981.

TESSER, Charles D. A verdade na biomedicina, reações adversas e efeitos colaterais: uma reflexão introdutória. Physis, Rio de Janeiro, v. 17, n. 3, p. 465-484, 2007.

YOUNG. Allan. Some implications of Medical Beliefs and Practices for Social Anthropology. American Anthropologist, v. 78, n. 1, p. 5-24, 1976.

\section{Notas}

${ }^{1} \mathrm{O}$ projeto de pesquisa que deu origem ao estudo foi aprovado pelo Comitê de Ética em Pesquisa da Secretaria de Estado de Saúde do Distrito Federal. A pesquisa foi conduzida dentro dos padrōes éticos exigidos pela Comissão Nacional de Ética em Pesquisa do Conselho Nacional de Saúde, Ministério da Saúde, bem como pelo Código de Ética do Antropólogo.

${ }^{2}$ Tal pesquisa foi realizada no âmbito da produção de dissertação de mestrado, tendo esta sido defendida no ano de 2008 no Programa de Pós-Graduação em Antropologia Social da Universidade de Brasília. Por meio de bolsa de estudos, foi financiada com recursos do Conselho Nacional de Desenvolvimento Científico e Tecnológico (CNPq). A pesquisa não envolveu nenhum conflito de interesses.

${ }^{3}$ Para mais detalhes sobre os itinerários terapêuticos e descrição de relatos de pacientes, ver Pereira (2008). 
${ }^{4}$ Para mais detalhes acerca da instituição e do desenvolvimento da pesquisa, ver Pereira (2008).

5 Há que se entender que geralmente os pacientes desconhecem as causas de suas doenças desde uma perspectiva médica, mas que de forma igualmente comum estabelecem discursos sobre suas causas sociais. Todavia, como pretendemos demonstrar na sequência do texto, essas vão perdendo importância ao longo do tempo. Com efeito, se de um modo geral não deixam de ser relevantes, certamente perdem muito valor do ponto de vista do desenvolvimento do tratamento médico, sustentando alguma importância no que diz respeito às consideraçôes do paciente para com o lugar da doença no sentido da vida e/ou da sua experiência.

${ }^{6}$ A posição dos exames nos tratamentos, estando inserida na problemática mais ampla do manejo de "verdades" pela ação médico-científica, inevitavelmente nos solicita um olhar panorâmico acerca do estatuto da produção destas "verdades" pela medicina. Sabe-se que, por razões tanto epistemológicas quanto éticas, a operacionalização dessas "verdades" implica dilemas diversos para a prática clínica (TESSER, 2007). Este artigo, contudo, objetiva iluminar certa contrapartida desse aspecto, ou seja, as formas como os pacientes interpretam e experimentam o surgimento e os efeitos dessas "verdades" ao longo de seus tratamentos.

${ }^{7}$ Sobre o "papel de doente" ver, sobretudo, Parsons (1951).

${ }^{8}$ Dupuy e Karsenty argumentaram que os pacientes ignorariam como poderiam, mudando de médico, encontrar um melhor do que o anterior. Além disso, acrescentaram que o único dispositivo de controle da qualidade dos atos médicos possuído pelos pacientes seria a verificação do diploma universitário do profissional (1974p. 134, 142).

${ }^{9}$ Goffman discutiu esta questão relacionando-a ao que chamou de "tratamento de não-pessoa". Diz ele: "A solução de não-pessoa parece muito eficiente quando o médico que faz o exame está acompanhado por colegas e subordinados - por exemplo, quando faz 'visitas' no hospital - pois nesse caso terá participantes para uma conversa técnica a respeito do caso. Essa maneira de suprimir a presença social do paciente é tão eficiente que seu destino pode ser abertamente discutido à sua cabeceira, sem que os debatedores sintam uma preocupação desnecessária; um vocabulário técnico, presumivelmente desconhecido pelo paciente, ajuda a criar essa situação" (1961, p. 278). Outra abordagem iluminadora poderia ser encontrada em Elias (1939) em sua discussão sobre a menor pressão exercida nos indivíduos para com o controle de seus impulsos quando se veem diante de outros de classes sociais inferiores comparada àquela existente quando se deparam com seus pares. 


\section{Uncertainties of Patients in the Brazilian Public Health System}

Analyses aiming to understand how subjects deal with processes of health/disease usually emphasize the ways in which they introduce their concrete experiences into abstract evaluative frames, in order to define actions to be implemented. This being stated, this paper questions the efficiency of such approaches in understanding the experiences of the patients of Brazilian's public health system. The analyses are undertaken based on the results of research made in a public health institution of the Brazilian Federal District, in which therapeutic itineraries of its patients were reconstituted. The research indicated that their trajectories are crossed by several orders of uncertainties. Considering their relevance and the fact that in any way it impedes the promotion of their medical treatment, the paper discusses how patients deal with these uncertainties and which relationships are established with the ensemble of their experiences. It is then argued that their uncertainties do not come from the inherent characteristics of the patients but from the relations they establish with (1) the medical knowledge and (2) the institutional organizations in which this knowledge is accomplished by the public health institutions. Further it shows that the patients' assessments, classifications etc. are not mainly directed to the processes of health/disease in the strict sense, but to the mechanisms that allow more successful relationships with the institutional organizations through which they receive their treatment.

> Key words: experiences of health/illness, uncertainties, patients of the Brazilian public health system. 